\title{
OPEM
}

www.opem.org

Oriental Pharmacy and Experimental Medicine 2008 7(5), 494-500

DOI 10.3742/OPEM.2008.7.5.494

\section{The anti-hypertensive effect of ginseng in patients with mild hypertension}

\author{
Young Suk Kim, Woo Sang Jung*, Seong Uk Park, Sang Kwan Moon, Jung Mi Park, Chang Nam Ko, \\ Ki Ho Cho and Hyung Sup Bae
}

Department of Cardiovascular \& Neurologic Diseases (Stroke Center), College of Oriental Medicine, Kyung-Hee University, Seoul, Korea

\begin{abstract}
SUMMARY
Ginseng has been traditionally used to recover vital energy from Qi deficiency in oriental countries. Recent reports suggested that ginseng could regulate blood pressure (BP), but much controversy still remain. Therefore, we intended to assess the anti-hypertensive effect of some ginseng species on Koreans and Chinese. This is a randomized, double blinded controlled clinical trial. The study subjects were recruited from the mild hypertensive patients who belonged prehypertension $(120 / 80$ to $139 / 89 \mathrm{mmHg})$ and stage I hypertension $(140 / 90$ to $159 / 99 \mathrm{mmHg})$ in Korea and China. After assigning the subjects into a Korean, a Chinese, and an American ginseng group by randomization, we prescribed ginseng with the dose of $4.5 \mathrm{~g}$ per a day for $4 \mathrm{w}$. To assess the anti-hypertensive effect, we compared the mean of systolic and diastolic BP between before and after ginseng medication by $24 \mathrm{~h}$ Ambulatory Blood Pressure Monitor ( $24 \mathrm{~h} \mathrm{ABPM})$. We also monitored adverse effect and laboratory findings to secure the subjects' safety. There were 64 subjects treated with Korean ginseng, 58 treated with Chinese ginseng, and 64 treated with American ginseng. All of the ginseng species reduced subjects' BP. Especially, Korean and Chinese ginseng showed more excellent effects. The secondary analysis on the subjects' nationality revealed that all of the ginseng species showed more significant anti-hypertensive effect in Chinese than in Koreans. We suggest ginseng could be useful for mild hypertension regardless of its species. And it would be safe within the dosage of $4.5 \mathrm{~g}$ per a day.
\end{abstract}

Key words: Panax ginseng; Hypertension; Panax Quinquefalium

\section{INTRODUCTION}

For thousands of years, herbs have been used for various medical fields in Asia. In spite of their actual effectiveness, much of them have not yet been fully understood or appreciated by western biomedicine. However, their mechanism and

\footnotetext{
*Correspondence: Woo Sang Jung, Department of Cardiovascular and Neurologic Diseases (Stroke Center), Hospital of Oriental Medicine, Kyung Hee Medical Center, 1 Hoegi-dong, Dongdaemun-gu, Seoul 130-702, Korea. Tel: +82029589289; FAX: +82029589132; E-mail: wsjung@khu.ac.kr
}

applications have appeared with increasing frequency in literature of basic and clinical science. Ginseng is one of them. According to Oriental Medical theory, it is believed to have aphrodisiac and beneficial effect on everything from energy deficiency of human beings by relieving fatigue, mental and nervous exhaustion. It is helpful for increasing quality of life by improving the body's resistance to stress and increasing vitality (Ellis and Reddy, 2002; Coleman et al., 2003).

Previous studies revealed that Ginseng has antioxidative effect (Friedl et al., 2001; Jeong et al., 2005; Jung et al., 2005), anti-cancer effect (Sohn et al., 1998; 
Chang et al., 2003; Helms, 2004), anti-stress effect (Rai et al., 2003), and anti-aging effect (Watanabe et al., 1991). It also has various biomedical effects on digestive function (Belogortseva et al., 2000; Jeong, 2002), cognitive function (Wesnes et al., 1997; Kennedy et al., 2004), muscular function (Ferrando et al., 1999), immune system (Yoshizato et al., 1999; Langhansova et al., 2004), endocrine system (Kim et al., 1990; Shin et al., 2002; Lim et al., 2004), reproductive system (Salvati et al., 1996; Hwang et al., 2004), and vascular system (Kuo et al., 1990; Park et al., 1995; Huang et al., 2005).

Recently, the possibility that ginseng could regulate blood pressure has been suggested. In the experimental studies, ginseng decreased blood pressure and pulse rate in hypertensive rats (Jeon et al., 2000), and improved pulmonary hypertension by reducing vascular resistance and elevating cardiac output (Jin et al., 1995). In the clinical studies, ginseng increased forearm blood flow measured by plethysmography (Sung et al., 2000), and relaxed myocardial function by inhibiting intracelluar calcium over load and reducing left ventricular muscle mass (Feng et al., 1997). Furthermore, in a randomized controlled clinical trial with $24 \mathrm{~h}$ ambulatory blood pressure monitor, it showed significant anti-hypertensive effect compared to the control (Han et al., 1998).

The most popular species of ginseng are Korean ginseng, Chinese ginseng and American ginseng. Korean ginseng is the raw material of 4 years old Panax ginseng roots grown in Korean and Chinses ginseng is the same materials but grown in China. American Ginseng is the raw material of 4 years old Panax Quinquefalium roots grown in North America. These are now used indiscriminately because little is known about the difference among the species.

Therefore, we intended to assess the clinical antihypertensive effect of ginseng on hypertension, and compare the effect among ginseng species. Additionally, we also investigated the anti-hypertensive effect by Korean and Chinese.

\section{MATERIALS AND METHODS}

\section{Subjects}

The population of this study was based on northeast Asia: Korea and China. We included the patients with mild hypertension in which blood pressure (BP) ranged from $120 / 80 \mathrm{mmHg}$ to $159 /$ $99 \mathrm{mmHg}$. These belong to pre-hypertension and stage I hypertension in the seventh report of the joint national committee on prevention, detection, evaluation, and treatment of high blood pressure express. In Korea, we recruited 123 subjects at the Department of Cardiovascular \& Neurologic Diseases (Stroke Center) of Kyung Hee Oriental Medical Hospital, from June 2004 to October 2004, and In China, 96 subjects were recruited at the Emergency Room of Teaching Hospital of The Traditional Chinese Medicine of Chengdu University, from July 2004 to April 2005. Exclusion criteria were severe diabetes mellitus, renal failure, pregnancy, secondary or malignant hypertension, and cardiovascular disease within 3 months.

\section{Materials}

Ginseng materials were supplied by the Korean National Agricultural Cooperative Federation (NACF). To guarantee the safety, we investigated the remaining agricultural chemicals from the materials (Table 1). And then we capsulated the materials (375 mg per one capsule) after reducing to powder.

\section{Procedures}

We included the eligible subjects after assessing general characteristics and their BP by the $24 \mathrm{~h}$ ambulatory blood pressure monitor (24 h ABPM). And then we prescribed ginseng $4.5 \mathrm{~g}$ (12 capsules) a day for $4 \mathrm{w}$ after assigning the subjects into a Korean, a Chinese, and an American ginseng group by randomization stratified by sex, age, and the mean BP obtained from $24 \mathrm{~h}$ monitoring.

To assess the anti-hypertensive effect of ginseng, we rechecked the subjects' BP by the $24 \mathrm{~h}$ ABPM, 
Table 1. Remaining agricultural chemicals from Korean, Chinese, Red, and American ginseng used in this study

\begin{tabular}{ccccc}
\hline Agricultural chemicals name & Permitted limit $(\mathrm{ppm})$ & Chinese ginseng & American ginseng & Korean ginseng \\
\hline BHC & 0.2 & 0.007 & ND & ND \\
DDT & 0.1 & ND & ND & ND \\
Aldrin/Diedrin & 0.01 & ND & ND & ND \\
Endrin & 0.01 & ND & ND & ND \\
Quintozene & 1.0 & 0.009 & 0.590 & 0.107 \\
Endosulfan & 0.2 & ND & ND & 0.099 \\
Captan & 2.0 & ND & ND & ND \\
Parathion & 0.1 & ND & ND & ND \\
Diazinon & 0.1 & ND & ND & ND \\
Metalaxyl & 1.0 & - & - & - \\
Carbendazim & 0.5 & - & - & - \\
Deltamethrin & 0.02 & ND & ND & ND \\
Diethofencarb & 0.5 & ND & ND & ND \\
Cypermethrin & 0.1 & ND & ND & ND \\
Azoxystrobin & 0.5 & ND & ND & ND \\
TolyFluanid & 0.3 & ND & ND & ND \\
Tolclofosmethyl & 1.0 & 0.012 & ND & 0.088 \\
Difenoconazole & 0.2 & ND & ND & ND \\
Procymidone & 0.4 & ND & ND & 0.400 \\
\hline
\end{tabular}

Limits are based upon standard of dry ginseng; BHC: Benzene hexachloride; DDT: Dichloro-diphenyltrichloroethane; ND: No detected.

Table 2. Baseline assessment according to ginseng species

\begin{tabular}{lccc}
\hline & Korean ginseng $(\mathrm{n}=64)$ & Chinese ginseng $(\mathrm{n}=58)$ & American ginseng $(\mathrm{n}=64)$ \\
\hline Age, $\mathrm{yr}$ & $54.8 \pm 9.9$ & $55.0 \pm 9.7$ & $54.9 \pm 10.4$ \\
Sex $(\mathrm{M} / \mathrm{F})$ & $34 / 30$ & $29 / 29$ & $36 / 28$ \\
Medical history & & & \\
BP medication & 19 & 22 & 23 \\
Diabetes & 1 & 1 & 2 \\
Hyperlipidemia & 6 & 1 & 5 \\
Systolic BP, mmHg & $137.3 \pm 10.2$ & $136.8 \pm 9.3$ & $86.5 \pm 11.5$ \\
Diastolic BP, mmHg & $86.7 \pm 7.3$ & $85.9 \pm 6.5$ & $15.2 \pm 26.1$ \\
VAS on headache & $14.5 \pm 26.9$ & $9.0 \pm 21.3$ & \\
\hline
\end{tabular}

There is no significant difference by one-way ANOVA test for continuous variables and Chi-square test for categorical variables.

and also investigated the effect of ginseng on the symptoms related with hypertension such as headache after $4 \mathrm{w}$ of medication. We also monitored adverse effect and laboratory findings to secure the subjects' safety.

Informed consensus was given to all the subjects after a full explanation of the study, and the Institutional Review Board (IRB) of Kyung Hee
Oriental Medical Hospital approved this protocol on 17 May, 2004 (KOMC IRB 2004-01).

\section{RESULTS}

There were 64 subjects who had been treated with Korean ginseng, 58 treated with Chinese ginseng, and 64 treated with American ginseng. The baseline 
Table 3. Comparison of anti-hypertensive effect and the improvement on VAS by ginseng species

\begin{tabular}{cccc}
\hline & Korean ginseng $(\mathrm{n}=64)$ & Chinese ginseng $(\mathrm{n}=58)$ & American ginseng $(\mathrm{n}=64)$ \\
\hline Systolic BP, mmHg & & & \\
Baseline & $137.3 \pm 10.2$ & $136.8 \pm 9.3$ & $136.5 \pm 11.5$ \\
after 4 w & $132.3 \pm 15.6^{*}$ & $132.9 \pm 14.4^{*}$ & $134.4 \pm 14.1$ \\
Variance & $-5.0 \pm 16.1$ & $-3.9 \pm 14.8$ & $-2.1 \pm 12.5$ \\
Diastolic BP, mmHg & & & \\
Baseline & $86.7 \pm 7.3$ & $85.9 \pm 6.5$ & $86.6 \pm 6.5$ \\
after 4 w & $80.6 \pm 10.8^{\dagger}$ & $80.8 \pm 9.2^{\dagger}$ & $82.8 \pm 10.1^{\dagger}$ \\
Variance & $-6.1 \pm 11.2$ & $-5.1 \pm 9.5$ & $-3.8 \pm 8.6$ \\
VAS on headache & & & \\
Baseline & $14.5 \pm 26.9$ & $9.0 \pm 21.3$ & $15.2 \pm 26.1$ \\
after 4 w & $8.4 \pm 19.8^{*}$ & $5.3 \pm 15.4$ & $8.3 \pm 19.3^{\dagger}$ \\
Variance & $-6.0 \pm 19.8$ & $-3.6 \pm 21.2$ & $-6.9 \pm 18.2$ \\
\hline
\end{tabular}

There was no significant difference among the groups by one-way ANOVA test. ${ }^{*}: P<0.05, P<0.01$ by paired $t$-test vs. baseline.

Table 4. Comparison of anti-hypertensive effect and the improvement on VAS between Koreans and Chineses in Korean ginseng-treated group

\begin{tabular}{cccc}
\hline & Koreans $(\mathrm{n}=30)$ & Chinese $(\mathrm{n}=34)$ & Sig. $^{*}$ \\
\hline Systolic BP, mmHg & & & \\
baseline & $133.4 \pm 9.0$ & $140.8 \pm 10.2$ & 0.003 \\
after 4 w & $131.1 \pm 12.2$ & $133.4 \pm 18.2^{\dagger}$ & N.S. \\
variance & $-2.3 \pm 11.1$ & $-7.3 \pm 19.4$ & N.S. \\
Diastolic BP, mmHg & & & \\
baseline & $85.2 \pm 8.2$ & $89.0 \pm 6.2$ & N.S. \\
after 4 w & $83.2 \pm 9.3$ & $78.3 \pm 11.7^{\dagger}$ & N.S. \\
variance & $-2.0 \pm 9.4$ & $-9.7 \pm 11.6$ & 0.005 \\
VAS on headache & & & \\
baseline & $22.3 \pm 32.3$ & $7.5 \pm 18.8$ & N.S. \\
after 4 w & $15.0 \pm 26.0$ & $2.7 \pm 9.0$ & 0.018 \\
improvement & $-7.3 \pm 24.9$ & $-4.9 \pm 14.2$ & N.S. \\
\hline
\end{tabular}

*: Statistical significance was calculated by independent $t$-test; ${ }^{\dagger}: P<0.05$ by paired $t$-test vs. baseline.

assessment did not differ among the groups (Table 2). In the within-group analysis, Korean and Chinese ginseng reduced systolic and diastolic BP, and American ginseng showed anti-hypertensive effect on diastolic BP and reduced headache symptom. However, there was no statistical significance in the between-group analysis (Table 3).

On the analysis of the subjects' response between Koreans and Chinese according to ginseng species, it was revealed that Korean ginseng had no significant beneficial effect on Koreans, but it lowered systolic and diastolic BP in Chinese subjects. Especially, in diastolic BP, there existed significant difference between the Koreans and Chinese (Table 4). Chinese ginseng had little effect on Koreans, but it lowered diastolic BP and headache symptom in Chinese. There was a significant difference in anti-hypertensive effect on diastolic $\mathrm{BP}$ between Koreans and Chinese (Table 5). American ginseng showed a similar effect with Chinese ginseng. It reduced diastolic BP significantly more in Chinese than in Korea (Table 6). In safety assessment, 
Table 5. Comparison of anti-hypertensive effect and the improvement on VAS between Koreans and Chinese in Chinese ginseng-treated group

\begin{tabular}{cccc}
\hline & Koreans $(\mathrm{n}=28)$ & Chinese $(\mathrm{n}=30)$ & Sig. $^{*}$ \\
\hline $\begin{array}{c}\text { Systolic BP, mmHg } \\
\text { baseline }\end{array}$ & $132.5 \pm 9.8$ & $140.8 \pm 8.5$ & $<0.001$ \\
after 4 w & $130.6 \pm 9.3$ & $135.1 \pm 17.9$ & N.S. \\
$\begin{array}{c}\text { variance } \\
\text { Diastolic BP, mmHg }\end{array}$ & $-1.9 \pm 9.2$ & $-5.8 \pm 18.6$ & N.S. \\
baseline & & & \\
after 4 w & $84.6 \pm 7.6$ & $87.2 \pm 5.1$ & N.S. \\
variance & $83.8 \pm 7.9$ & $78.0 \pm 9.7^{\dagger}$ & 0.017 \\
VAS on headache & $-0.9 \pm 7.5$ & $-9.1 \pm 9.6$ & 0.001 \\
baseline & & & \\
after 4 w & $17.9 \pm 28.1$ & $0.7 \pm 3.7$ & 0.003 \\
improvement & $11.1 \pm 20.8$ & $0.0 \pm 0.0^{\dagger}$ & 0.009 \\
\hline
\end{tabular}

*: Statistical significance was calculated by independent $t$-test; ${ }^{\dagger}: P<0.05$ by paired t-test vs. baseline.

Table 6. Comparison of anti-hypertensive effect and the improvement on VAS between Koreans and Chinese in American ginseng-treated group

\begin{tabular}{cccc}
\hline & Koreans $(\mathrm{n}=32)$ & Chinese $(\mathrm{n}=32)$ & Sig. $^{*}$ \\
\hline Systolic BP, mmHg & & & \\
baseline & $134.5 \pm 11.8$ & $138.5 \pm 11.1$ & N.S. \\
after 4 w & $134.5 \pm 12.7$ & $134.3 \pm 15.6$ & N.S. \\
variance & $0.0 \pm 10.0$ & $-4.2 \pm 14.4$ & N.S. \\
Diastolic BP, mmHg & & & \\
baseline & $86.7 \pm 7.4$ & $86.6 \pm 5.7$ & N.S. \\
after 4 w & $85.7 \pm 8.6$ & $80.0 \pm 10.7^{\dagger}$ & 0.022 \\
variance & $-1.0 \pm 5.6$ & $-6.6 \pm 10.2$ & 0.010 \\
VAS on headache & & & \\
baseline & $22.8 \pm 30.0$ & $7.5 \pm 19.2$ & 0.018 \\
after 4 w & $15.6 \pm 24.9$ & $0.9 \pm 5.3$ & 0.003 \\
\hline improvement & $-7.2 \pm 19.0$ & $-6.6 \pm 17.7$ & N.S. \\
\hline
\end{tabular}

${ }^{\bar{*}}$ : Statistical significance was calculated by independent $t$-test; ${ }^{\dagger}: P<0.05$ by paired $t$-test vs. baseline.

there was no adverse effect and abnormal laboratory findings.

\section{DISCUSSION}

In this study, ginseng reduced subjects' BP. These results might be explained by the facts that it could reduce vascular resistance (Jin et al., 1995), and dilate lumen of vessels by inducing nitric oxide production in endothelial cell (Jeon et al., 2000) and inhibiting intracellular calcium over-load on erythrocytes membrane (Feng et al., 1997). Especially, Korean and Chinese ginseng showed more excellent effects. They reduced both of systolic and diastolic BP significantly, while American ginseng reduced only diastolic BP. These results could suggest that Panax ginseng is more useful for hypertenstion than Panax Quinquefalium. However, it is not strong enough to confirm this suggestion, because there was no statistical significance in the between-subjects analysis by ANOVA.

The secondary analysis on the subjects' nationality 
revealed that all of the ginseng species showed more significant anti-hypertensive effect in Chinese than in Koreans. From these results, we could think that the physicians in China seemed to help the patients to have more desirable life-style for controlling high BP, although all of the involved physicians in both of the nations were trained to adhere to the same protocol. It might be due to the fact that the Chinese physicians had to labor the point, because most of Chinese people were not used to clinical research. Furthermore, the Chinese physicians hardly managed to collect the volunteers because it is illegal to collect people by advertisement in China. We could also think that there still exists a possibility that the different genetic type made the different efficacy of ginseng between Korean and Chinese. However, the previous reports, in which ginseng had the same efficacy on $\mathrm{BP}$, pulse rate, and body temperature in Korean and Chinese (Seo et al., 2003, 2004), doesn't support this possibility.

In conclusion, we suggest Panax ginseng is useful for high BP, and all of the ginseng species, used in this study, are safe with the dosage of $4.5 \mathrm{~g}$ per a day.

\section{ACKNOWLEDGMENTS}

This research was supported by Korean National Agricultural Cooperative Federation in 2004.

\section{REFERENCES}

Belogortseva NI, Yoon JY, Kim KH. (2000) Inhibition of Helicobacter pylori hemagglutination by polysaccharide fractions from roots of Panax ginseng. Planta Med. 66, 217-220.

Chang YS, Seo EK, Gyllenhaal C, Block KI. (2003) Panax ginseng: a role in cancer therapy? Integr. Cancer Ther. 2, 13-33.

Coleman CI, Hebert JH, Reddy P. (2003) The effects of Panax ginseng on quality of life. J. Clin. Pharm. Ther. 28, 5-15.

Ellis JM, Reddy P. (2002) Effects of Panax ginseng on quality of life. Ann Pharmacother. 36, 375-379.

Feng PF, Qin NP, Qiao Q. (1997) Clinical and experimental study of improving left ventricular diastolic function by total saponins of panax notoginseng. Zhongguo Zhong Xi Yi Jie He Za Zhi 17, 714-717.

Ferrando A, Vila L, Voces JA, Cabral, AC Alvarez AI, Prieto JG. (1999) Effects of a standardized Panax ginseng extract on the skeletal muscle of the rat: a comparative study in animals at rest and under exercise. Planta Med. 65, 239-244.

Friedl R, Moeslinger T, Kopp B, Spieckermann PG. (2001) Stimulation of nitric oxide synthesis by the aqueous extract of Panax ginseng root in RAW 264.7 cells. Br. J. Pharmacol. 134, 1663-1670.

Han KH, Choe SC, Kim HS, Sohn DW, Nam KY, Oh BH, Lee MM, Park YB, Choi YS, Seo JD, Lee YW. (1998) Effect of red ginseng on blood pressure in patients with essential hypertension and white coat hypertension. Am. J. Chin. Med. 26,199-209.

Helms S. (2004) Cancer prevention and therapeutics: Panax ginseng. Altern. Med. Rev. 9, 259-274.

Huang YC, Chen CT, Chen SC, Lai PH, Liang HC, Chang Y, Yu LC, Sung HW. (2005) A natural compound (ginsenoside Re) isolated from Panax ginseng as a novel angiogenic agent for tissue regeneration. Pharm. Res. 22, 636-646.

Hwang SY, Kim WJ, Wee JJ, Choi JS, Kim SK. (2004) Panax ginsengimproves survival and sperm quality in guinea pigs exposed to 2,3,7,8-tetrachlorodibenzo p-dioxin. BJU Int. 94, 663-668.

Jeon BH, Kim CS, Park KS, Lee JW, Park JB, Kim KJ, Kim SH, Chang SJ, Nam KY. (2000) Effect of Korea red ginseng on the blood pressure in conscious hypertensive rats. Gen. Pharmacol. 35, 135-141.

Jeong CS. (2002) Effect of butanol fraction of Panax ginseng head on gastric lesion and ulcer. Arch. Pharm. Res. 25, 61-66.

Jeong GT, Park DH, Ryu HW, Hwang B, Woo JC, Kim D, Kim SW. (2005) Production of antioxidant compounds by culture of Panax ginseng C.A. Meyer hairy roots: I. Enhanced production of secondary metabolite in hairy root cultures by elicitation. Appl. Biochem. Biotechnol. 121-124, 1147-1157.

Jin XQ, Duan SF, Niu RJ. (1995) Effect of shen mai injection and its combinations on blood gas and hemodynamics of rats exposed to chronic hypoxia. Zhongguo Zhong Xi Yi jie He Za Zhi 15, 162-164. 
Jung $\mathrm{CH}$, Seog HM, Choi IW, Choi HD, Cho HY. (2005) Effects of wild ginseng (Panax ginseng CA Meyer) leaves on lipid peroxidation levels and antioxidant enzyme activities in streptozotocin diabetic rats. J. Ethnopharmacol. 98, 245-250.

Kennedy DO, Haskell CF, Wesnes KA, Scholey AB. (2004) Improved cognitive performance in human volunteers following administration of guarana (Paullinia cupana) extract: comparison and interaction with Panax ginseng. Pharmacol. Biochem. Behav. 79, 401-411.

Kim JY, Germolec DR, Luster MI. (1990) Panax ginseng as a potential immunomodulator: studies in mice. Immunopharmacol. Immunotoxicol. 12, 257-276.

Kuo SC, Teng CM, Lee JC, Ko FN, Chen SC, Wu TS. (1990) Antiplatelet components in Panax ginseng. Planta Med. 56, 164-167.

Langhansova L, Konradova H, Vanek T. (2004) Polyethylene glycol and abscisic acid improve maturation and regeneration of Panax ginseng somatic embryos. Plant Cell Rep. 22, 725-730.

Lim TS, Na K, Choi EM, Chung JY, Hwang JK. (2004) Immunomodulating activities of polysaccharides isolated from Panax ginseng. J. Med. Food 7, 1-6.

Park HJ, Rhee MH, Park KM, Nam KY, Park KH. (1995) Effect of non-saponin fraction from Panax ginseng on cGMP and thromboxane A2 in human platelet aggregation. J. Ethnopharmacol. 49, 157-162.

Rai D, Bhatia G, Sen T, Palit G. (2003) Anti-stress effects of Ginkgo biloba and Panax ginseng: a comparative study. J. Pharmacol. Sci. 93, 458-464.

Salvati G, Genovesi G, Marcellini L, Paolini P, De Nuccio I, Pepe M, Re M. (1996) Effects of Panax Ginseng C.A. Meyer saponins on male fertility. Panminerva Med. 38, 249-254.

Seo JC, Huh JG, Han SW, Lee KY, Byun JS, Kim MS, Hah ID, Yim KH. (2003) The effects of Korean ginseng and American ginseng on body temperature in Koreans and Chinese. Orient. Physiol. Pathol. 17, 837-841.
Seo JC, Lee SY, Lee KM, Yim SC, Jung TY, Ahn HD, Han SW, Hah ID, Huh JG, Lee KY, Kim MS. (2004) The effects of Korean ginseng and American ginseng on blood pressure and pulse rate in Koreans and Chinese. Orient. Physiol. Pathol. 18, 606-611.

Seol YK, Kim JW. (2002) A Comparative Study on the Characteristics According to the Sasang Constitution. J. Sasang Constitutional Med. 14, 45-57.

Shin JY, Song JY, Yun YS, Yang HO, Rhee DK, Pyo S. (2002) Immunostimulating effects of acidic polysaccharides extract of Panax ginseng on macrophage function. Immunopharmacol. Immunotoxicol. 24, 469-482.

Sohn J, Lee CH, Chung DJ, Park SH, Kim I, Hwang WI. (1998) Effect of petroleum ether extract of Panax ginseng roots on proliferation and cell cycle progression of human renal cell carcinoma cells. Exp. Mol. Med. 30, 47-51.

Song IB, Park KS. (2002) Sasang Constitutional Medicine and Incurable Disease. J. Sasang Constitutional Med. 14, 1-6.

Sung J, Han $\mathrm{KH}$, Zo JH, Park HJ, Kim $\mathrm{CH}$, Oh BH. (2000) Effects of red ginseng upon vascular endothelial function in patients with essential hypertension. Am. J. Chin. Med. 28, 205-216.

Watanabe H, Ohta H, Imamura L, Asakura W, Matoba Y, Matsumoto K. (1991) Effect of Panax ginseng on age-related changes in the spontaneous motor activity and dopaminergic nervous system in the rat. Jpn. J. Pharmacol. 55, 51-56.

Wesnes KA, Faleni RA, Hefting NR, Hoogsteen G, Houben JJ, Jenkins E, Jonkman JH, Leonard J, Petrini O, van Lier JJ. (1997) The cognitive, subjective, and physical effects of a ginkgo biloba/panax ginseng combination in healthy volunteers with neurasthenic complaints. Psychopharmacol. Bull. 33, 677-683.

Yoshizato H, Fujikawa T, Shibata M, Tanaka M, Nakashima K. (1999) Stimulation of growth hormone gene expression in the pituitary and brain by Panax ginseng C. A. MEYER. Endocr. J. 46 Suppl, S85-88. 